\title{
6
}

\section{Parasitic Worms and Population Cycles of Red Grouse}

Peter J. Hudson, Andy P. Dobson, and David Newborn

\subsection{Historical Introduction to Grouse Research}

Many years before Charles Elton collected the detailed data on fur returns to The Hudson's Bay Trading Company, or described the regular fluctuations in small mammal numbers, scientists and naturalists had observed and were proposing explanations for the cause of periodic crashes in numbers of red grouse known as "grouse disease." MacDonald (1883) claimed "that it was more than eighty years since the alarm of grouse disease was sounded in this country," implying that naturalists were starting to examine the phenomenon nearly 200 years ago. In 1873, The House of Commons established a Select Committee to consider the game laws of the United Kingdom and, since this had followed a year of particularly severe population collapse in red grouse numbers, they took exhaustive evidence on a wide range of possible causes of "grouse disease." An examination of the letters in The Times and The Field shows that the debate over the cause of the population crashes was contentious and as heated as many of the recent debates over the causes of population cycles.

Scientific studies were initiated by Cobbold (1873) who examined grouse killed during a population crash, published a pamphlet that described the presence of large numbers of "strongle worms," and advocated the theory that the cause of grouse disease was wholly due to the presence of nematode worms. In 1905, the Board of Agriculture appointed a Committee of Inquiry on Grouse Disease to investigate the life history of the parasite and the causes of "grouse disease." The extensive survey and detailed analysis was quite remarkable for the time, and was presented in a two-volume publication 
(Lovat 1911). The Committee surveyed grouse populations, undertook experiments and, after nearly 2000 dissections, came to the conclusion that "the strongyle worm, and the strongyle worm alone, is the immediate causa causans of adult 'Grouse Disease." The Principal Field Officer was E. A. Wilson, a gifted artist and scientist who was later appointed as the Scientific Director to Captain Scott's Antarctic expedition on the Terra Nova. Unfortunately, Wilson never saw the production of the final report as he died with Scott during the return from the South Pole.

Mackenzie (1952) presented and described the bag records of grouse species shot in the United Kingdom, and Moran (1952) undertook time series, analysis that described the tendency of the populations to show regular oscillations. Lack (1954) was concerned that the oscillations were not as regular as the Canadian lynx time series, and postulated that the main cause of the cycles was an interaction between parasites and food. He based this idea not on new data, but on a reading of the main report by the Inquiry on Grouse Disease (Lovat 1911). The red grouse remained a focus of population research and, in 1956, Professor Wynne-Edwards established a unit of Aberdeen University to "test the Animal Dispersion Hypothesis." Later, as his ideas on group selection were generally dismissed, workers focused on the role of spacing behavior in the population dynamics of red grouse. After 30 years of detailed work, Wynne-Edwards (1986) summarized his perspective on the findings thus:

"Grouse disease as a lethal epidemic was a misunderstanding: instead, as predicted at the outset, it's the birds themselves that by mutual competition determine their own population density.... The successful ones occupy the habitat in a virtually continuous mosaic. The surplus ones become outcasts, and expendable; all of them are normally dead from secondary causes before the spring when breeding starts. 'Grouse disease' was a mistaken diagnosis of the after effects of social exclusion."

This statement is in direct contrast with the clear statement given by Lovat (1911), and underemphasizes the detailed experiments and monitoring that has been undertaken on the role of spacing behavior by the workers in northeast Scotland. Since this book is concerned with the hypothesis that grouse cycles are caused by trophic interactions, we will not review the large literature on the possible role of spacing behavior in grouse population dynamics (see, e.g., Moss and Watson 1991).

By the 1970s it was generally accepted amongst population biologists that spacing behavior determined grouse density and that grouse disease was a consequence of the behavior of the birds. This idea fitted the belief portrayed in text books that in "natural systems" parasites were selected to be benign to their hosts and not to have an important long-term impact on host dynamics (e.g., Ricklefs 1979). However, Anderson and May (1978) synthesized the disciplines of population biology and parasitology to provide a sound mathematical framework that captured the dynamics of the parasite-host relationship. They specifically identified the destabilizing characteristics of the 
parasite-host relationship that would generate oscillations in host abundance. Their models showed that a random or regular distribution of parasites in the host population, parasite-induced reduction in host fecundity, and time delays in parasite development would all destabilize a host population, although the final dynamics would be a consequence of the tension between these processes and other stabilizing mechanisms. Interestingly, their work highlighted the importance of parasite-induced reduction in host fecundity and emphasized that, depending on the relative degree of parasite aggregation within the host population, this had to be larger than the relative impacts on survival. This observation is interesting in the context of the previous studies on "grouse disease," where workers considered only the lethal effects of parasites and not the sublethal effects that provided a more focused explanation of red grouse cycles.

From this historical perspective the question arises "What are the sublethal effects of parasites on red grouse and what role do they play in the population dynamics of red grouse?" The social behavior hypothesis proposes that parasites are a consequence of the effects of social exclusion (Jenkins et al. 1963). In contrast, the parasite hypothesis suggests that parasites reduce fecundity of grouse in a way that causes the grouse population to cycle in abundance. This chapter examines this hypothesis in more detail and summarizes a series of published studies (Hudson et al. 1985, 1992a,b, 1999, Hudson 1986a,b, 1992, Dobson and Hudson 1992, 1995, Hudson and Dobson 1996).

\subsection{Time Series Analysis}

Red grouse population time series occur in the form of bag records and sample counts within populations. Each privately owned grouse moor seeks to maximize its long-term hunting returns which, in reality, means harvesting to a level where a suitable breeding stock is left for the following year. Hunting is not regulated, and the individual landowner decides how many birds can be harvested. For more than 150 years, landowners have kept detailed and accurate counts of numbers harvested each year on different managed estates. Since each is managed independently and often separated from others by natural watersheds, workers have tended to consider each time series as independent. Population counts show that bag records are usually a fair reflection of abundance (figure 6.1), although since hunting takes place in the fall, approximately two thirds of the harvest is of immature birds and so breeding production influences bag records. Overall, the variance in hunting mortality is greater at population densities less than $100 \mathrm{birds} / \mathrm{km}^{2}$, probably because grouse are aggregated and counts less accurate at low densities (Hudson et al. 1999).

Time series analysis of the bag records shows that the majority of time series (Potts et al. 1984, Hudson et al. 1985, Hudson 1992) show significant autocorrelation coefficients at half the cycle period, which is typical of phase-forgetting quasi-cycles (Gurney and Nisbett 1998). Significant partial 


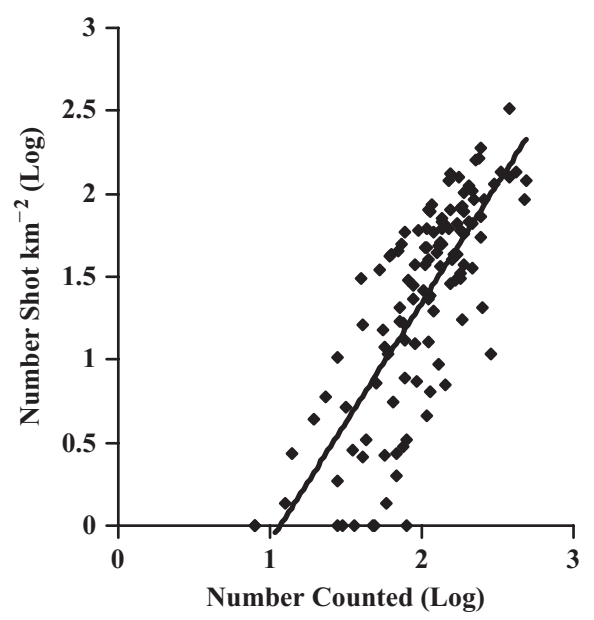

Figure 6.1 Relationship between grouse harvest and population density per square kilometer. While there is evidence that hunting records at a large scale reflect density estimates at a lower scale, the variance in the counts is greater at densities less than 100 birds $/ \mathrm{km}^{2}$. This is because at low grouse densities grouse are aggregated and the count areas do not reflect this aggregation well (Hudson et al. 1999).

autocorrelation coefficients indicate a second-order density dependence, and spectral analysis shows that most populations produce cycles with a period of between 4 and 6 years (figure 6.2). Generally, the cycle period increases with latitude, with longer cycles in Scotland than in England, and this is apparently associated with lower breeding production in the north. Not all populations produce cyclic bag records. Those from small areas of moorland and on the drier, eastern side of the country have a lesser tendency to oscillate (Hudson et al. 1985, Hudson 1992). This is important, since any explanation for the cause of cycles must account for why some populations are cyclic and others are not, and must also explain variations in cycle period.

\subsection{Nematode Parasites}

Originally described by Cobold (1873) as Trichostrongylus pergracilis, the grouse cecal nematode was later included with Trichostrongylus tenuis (Mehlin 1846). The nematodes inhabit the large blind-ending ceca of red grouse, where they cause internal inflammation and bleeding (Watson et al. 1987). The parasite has a direct lifecycle with no intermediate hosts. Adults produce eggs at a constant rate with no evidence of density-dependent fecundity (Hudson and Dobson 1996). The first two larval stages stay within the feces, and the third stage infective larvae retain the sheath of 
(a) Time series and detrended line

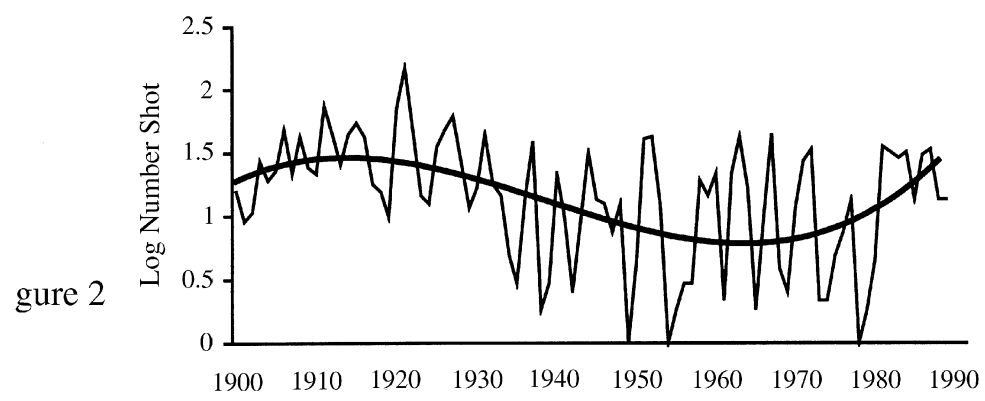

(b) Partial Autocorrelation Function

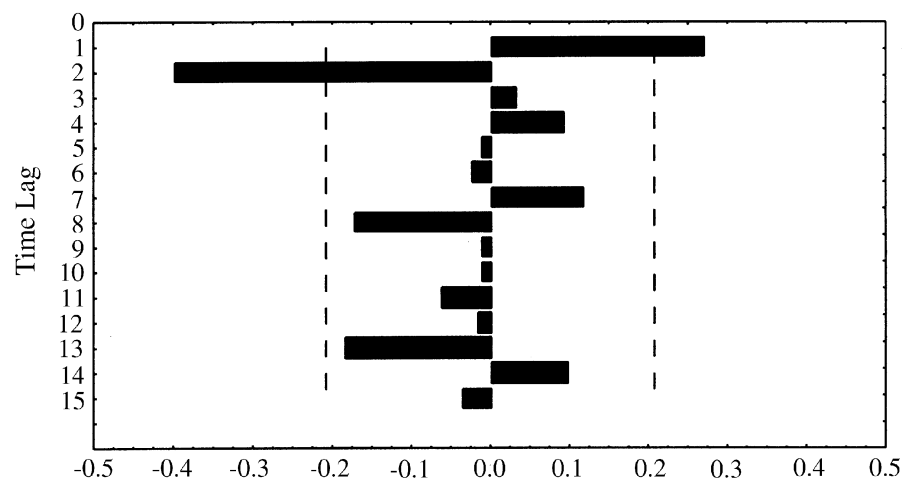

(c) Spectral Analysis: Cycle Period

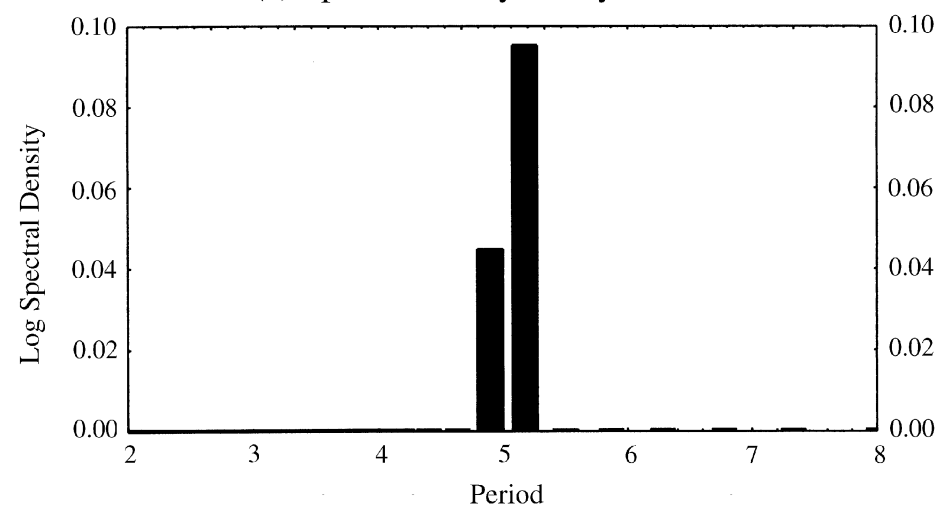

Figure 6.2 Time series analysis of grouse harvesting records. (a) Numbers shot per annum is nonstationary, so the time series was detrended using a third-order polynomial, and the residuals used for the analysis. (b) Partial autocorrelogram with Bartlett lines indicating the level of significance. (c) Smoothed spectral analysis of time series indicating a cycle period of approximately 5 years. 
the second larval stage, leave the cecal pat, and ascend the growing shoots of the principal food plant of red grouse, heather Calluna vulgaris (Saunders et al. 1999, 2000). The larval stage requires moist conditions for development and to aid mobility up the plant (Hudson 1986b, Saunders et al. 1999), and infection occurs when the grouse eat the growing tips. Uptake of worms by immature grouse occurs principally during July and August, when temperature allows development (Hudson 1996, Hudson and Dobson 1996). Some infective stages may shed the coat of the second larval stage and remain dormant in the gut mucosa before commencing development in late winter (Shaw 1988). The parasites show an aggregated distribution within the adult host population (Hudson et al. 1992a), although the degree of aggregation is weak $(k$ of the negative binomial $=1)$ compared with the majority of parasitic infections (Shaw and Dobson 1995). This is probably a consequence of the low level of acquired resistance within the host population (Hudson and Dobson 1996).

To relate changes in the population to changes in parasite burdens, red grouse numbers have been carefully monitored annually since 1979 on $1 \mathrm{~km}^{2}$ plots. Sample counts are taken every spring to record breeding density and in July to record number of chicks reared per female. The per-capita rate of change of the population decreases, and breeding mortality increases, as the intensity of worm infection increases (figure 6.3). Replicated field experiments have shown that grouse with experimentally reduced infections have higher brood production and survival (Hudson 1986b, Hudson et al. 1992a). This finding shows that parasitic infections reduce grouse breeding production, and is in line with the model of May and Anderson (1978), which predicts that parasite-induced reduction in host fecundity is destabilizing.

\subsection{Population Model}

Dobson and Hudson (1992) explored the dynamics of the interaction between red grouse and $T$. tenuis with Anderson-May models. We incorporated a third equation to describe changes in the size of free-living parasites and included a description of arrested larval development. The model is based on the lifecycle of the parasite and includes the parasiteinduced impacts on survival and brood production of the grouse, as determined by field experiments. Simulations with the model suggest that time delays caused by parasite-arrested development (or hypobiosis) are not the main cause of population oscillations. Cyclic oscillations in the model occur when the ratio of parasite-induced reduction in host fecundity to parasite-induced reduction in host survival is greater than the degree of parasite aggregation within the host population. In other words, the relative impact on fecundity destabilizes the host population and is the principal cause of the oscillation. The reproductive rate of the grouse and the life expectancy of the free-living stages determine the cycle period (figure 6.4). 
(a)

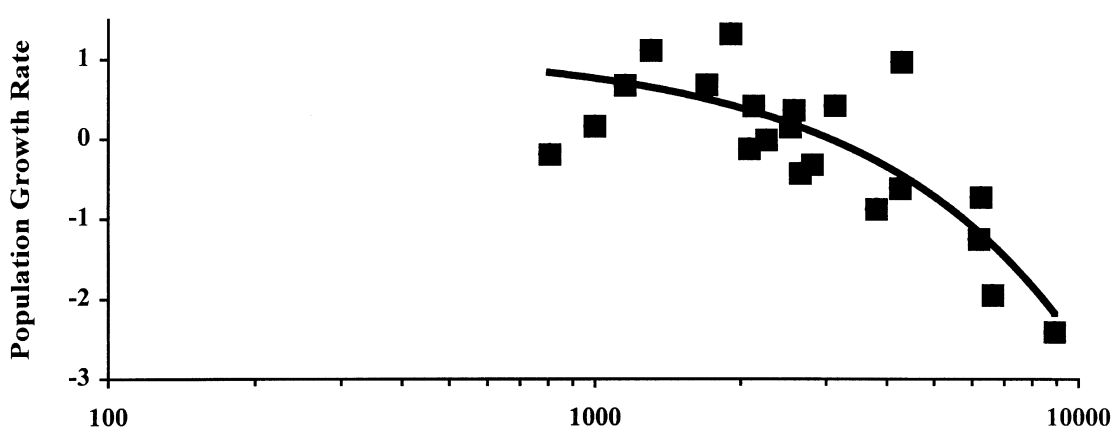

(b)

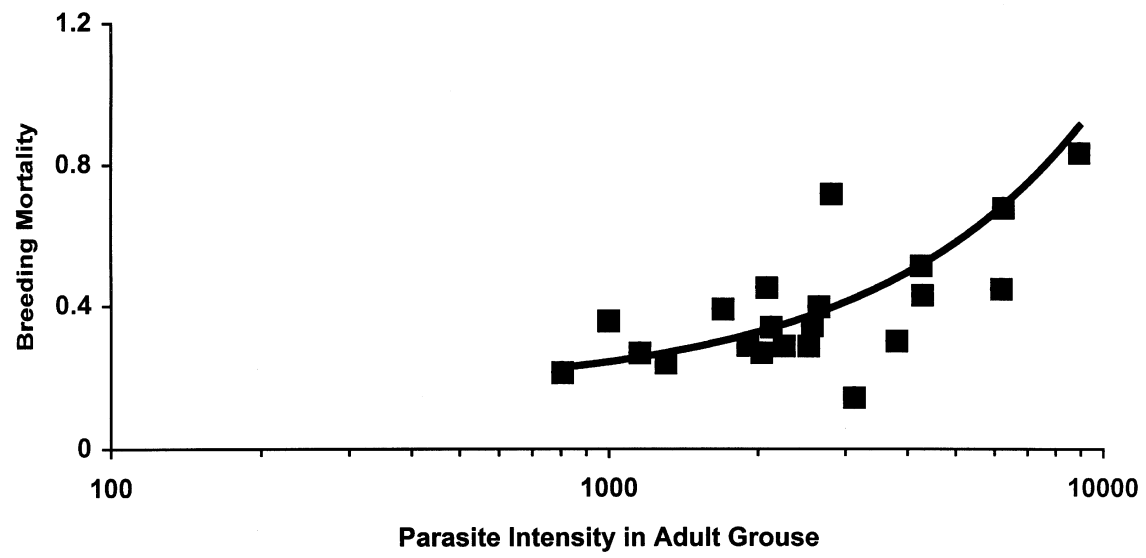

Figure 6.3 The relationship between geometric mean parasite intensities and population change. (a) Data from a 22-year longitudinal study of grouse populations. (b) Breeding mortality estimated as killing mortality (log difference, numbers of chicks at 6 weeks minus maximum clutch size taken as 12) in relation to geometric mean intensity of parasite infection in adult grouse.

The role of arrested development is interesting since this effectively adds a time delay between the production of the infective stage and the impact of the parasite, and it is well known that time delays can be destabilizing (May 1976). In this system, the time delay increases the cycle period but tends to dampen the oscillations. This occurs because the arrested larvae have no impact on their host until they emerge, but die when the host dies, effectively increasing the mortality of the free-living stages and dampening the oscillations (Dobson and Hudson 1992). 


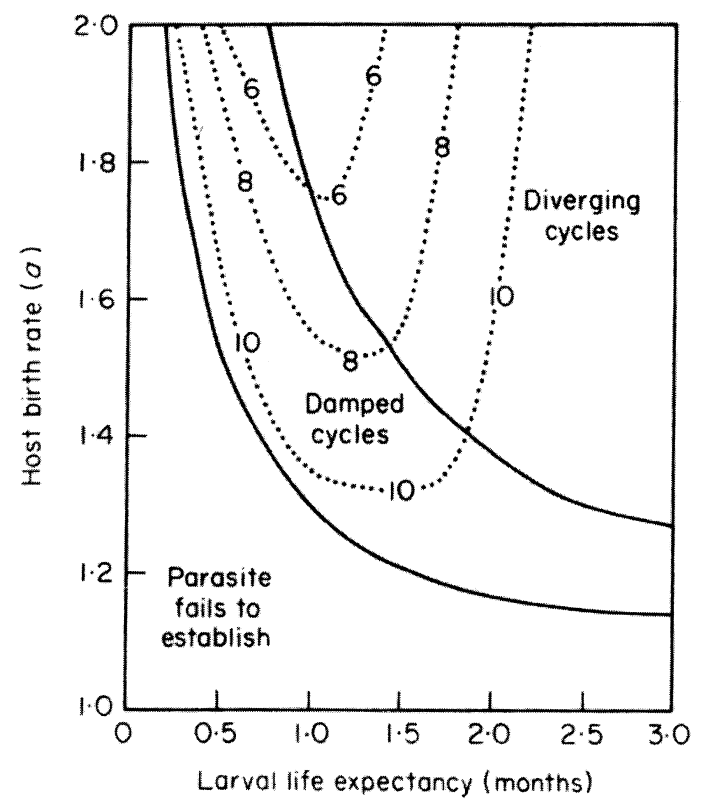

Figure 6.4 The influence of larval longevity and host fecundity on the dynamics of red grouse when there is no arrestment in the model of Dobson and Hudson (1992).

\subsection{Experiments}

Our simulation of the grouse-nematode interaction predicts that red grouse populations will cycle with a period of 5 to 10 years, and with an amplitude and pattern (slow up and fast down) similar to the observed time series. This suggests that the interaction with parasitic worms is a plausible hypothesis for the grouse cycle. The problem is, how to test this hypothesis to the exclusion of others. The model provides a possible way to do this: First, we included in the model a description of worm mortality caused by the application of the anthelmintic Levamisole hydrocholoride (Hudson et al. 1999). Second, we used the model to predict the level of treatment needed to suppress the large-amplitude cycles normally observed (figure 6.5a). Notice that we would need to treat more than $20 \%$ of the grouse population to have a large impact on grouse cycles, so our experiments were designed to treat $20 \%$ or more of the grouse population. It is interesting to note that removal of a small proportion of worms has a large influence on host dynamics, but worm eradication would require the treatment of nearly all grouse. The model identifies an interesting compensation similar to the paradox of enrichment. Treatment of the grouse reduces the size of the worm population but increases grouse fecundity, such that the grouse population rises and there are more hosts for the surviving parasites to infect. Consequently, the more grouse that 
(a)

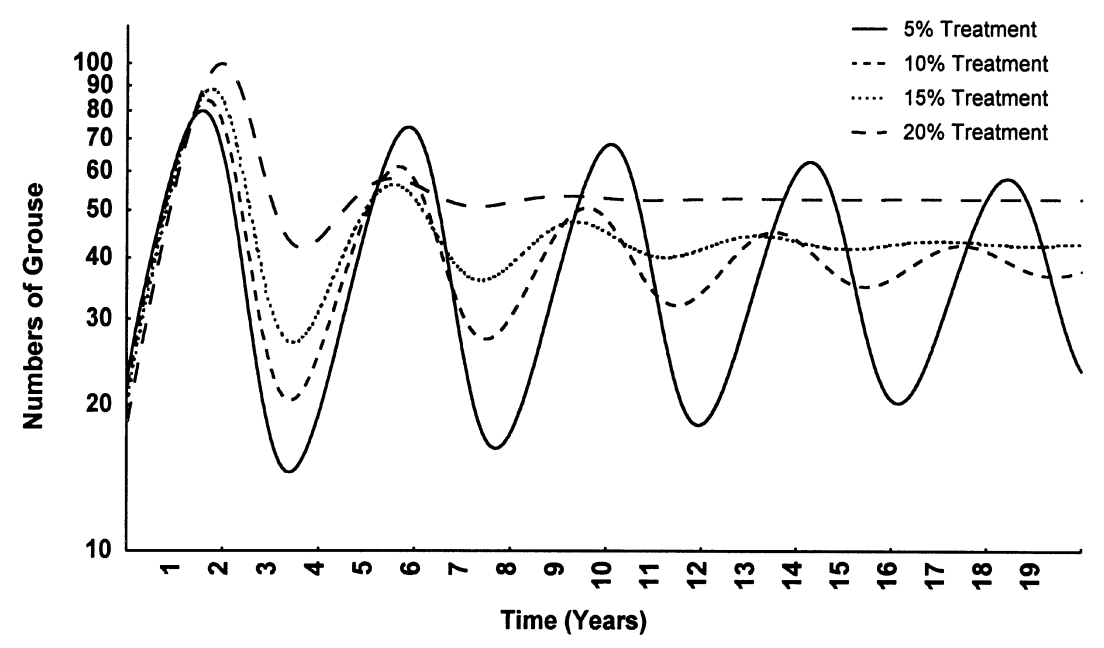

(b)

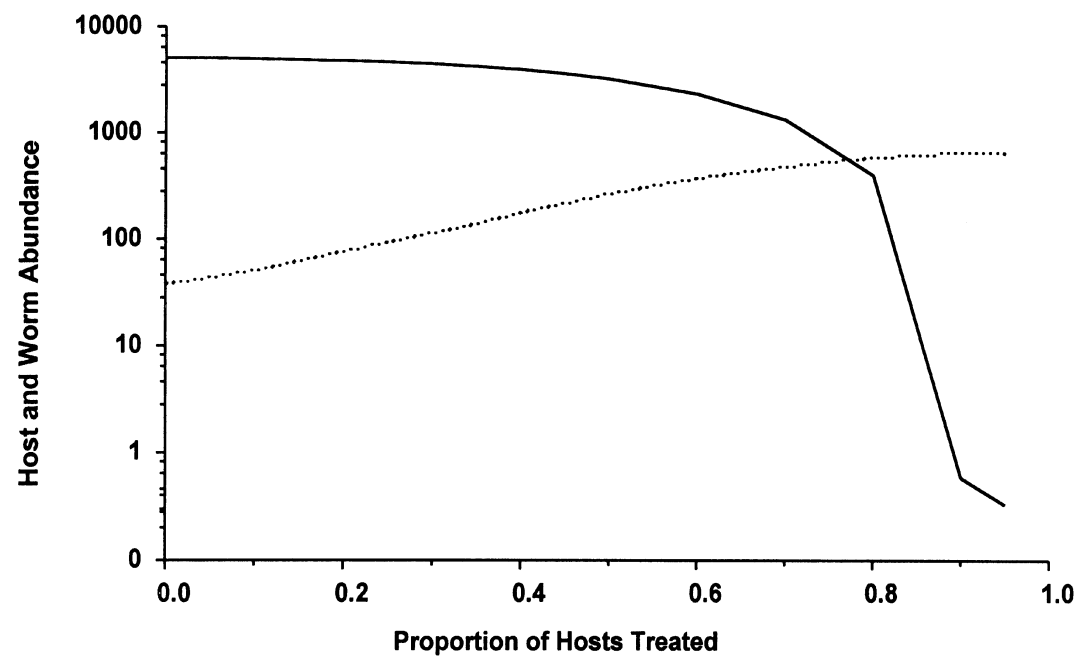

Figure 6.5 (a) Predicted decreases in cycle amplitude of grouse populations with increasing proportion of anthelmintic-treated grouse. (b) Equilibrium grouse and worm populations obtained by increasing levels of treatment with antihelmint. Treatment results in higher grouse fecundity and, consequently, an increase in transmission such that more than $96 \%$ of the population needs to be treated to eradicate the worms (after Hudson et al. 1999). 
are treated the greater the force of infection on the untreated birds and their offspring. Ultimately, eradication of the parasite requires that more than $90 \%$ of the grouse be treated (figure $6.5 \mathrm{~b}$ ).

\subsubsection{Experimental Methods}

Six study areas approximately $20 \mathrm{~km}^{2}$. in size were located in either North Yorkshire or County Durham in northern England in independently managed grouse populations. Using the model with previous estimates of grouse abundance and worm burdens, we predicted that the first crash would occur in 1989. During the winter before the crash large numbers of grouse were caught at night by dazzling the birds (Hudson and Newborn 1995). On four of the six study areas, grouse were treated orally with the anthelmintic Levamisole hydrochloride to reduce intensities of worm infection, and marked with a patagial wing flash. The remaining two populations were left untreated. On three of the treated populations, about $20 \%$ of the population were caught, treated, and tagged, but on the third only about $15 \%$ were treated. The next population crash was predicted in 1993, and in this year two of the previously treated areas were retreated. Bag records from managed estates were used to monitor changes in the grouse populations. Grouse bag records were used as a proxy for grouse abundance because resources were not available to monitor all sites in detail. The relationship between density estimated on $1 \mathrm{~km}^{2}$ areas and numbers harvested at a much larger scale $\left(20 \mathrm{~km}^{2}\right)$ is reasonably good (see figure 6.1 ).

\subsubsection{Results}

The overall effect of treating grouse with an anthelmintic was to reduce the collapse of the population from its peak (figure 6.6). Note that the amplitude of the cycle was suppressed on all treated plots, as predicted by the model (figure 6.5a); fewer grouse were harvested from the site where a lower proportion of grouse were treated, but this was expected from the model. In general, the removal of parasites reduced the amplitude of the oscillations implying that, on these sites and at these times, parasitism was responsible for the observed population fluctuations. Of course, our results do not prove that other factors could not be involved, on other sites or at other times, but leaves little doubt that parasites were the principal cause of population cycles on our study sites. We are now testing the hypothesis on other populations where parasites are not thought to be involved in the population cycles.

\subsubsection{Criticisms}

Proponents of the spacing hypothesis have criticized our experiment, particularly our contention that "these results show parasites were both sufficient and necessary in causing cycles in these populations" (chap. 9, Lambin et al. 


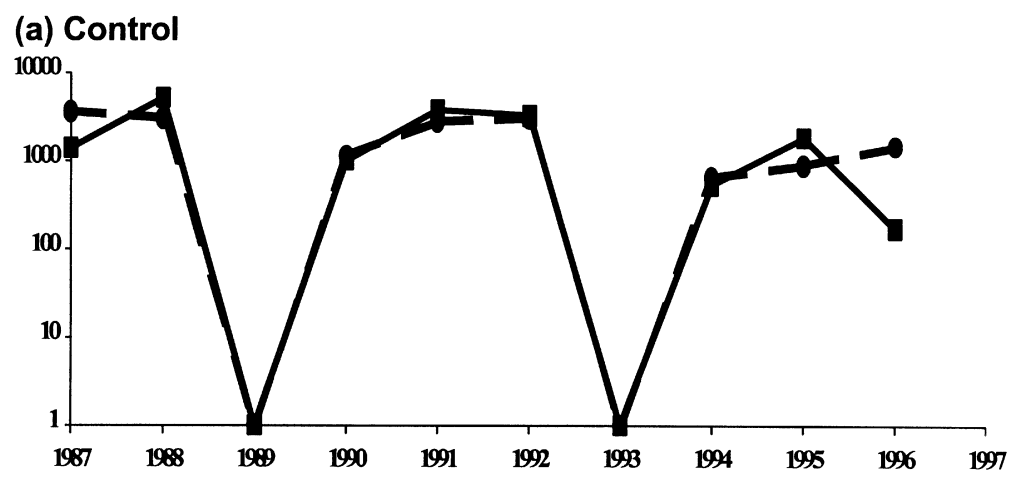

\section{(b) One Treatment}

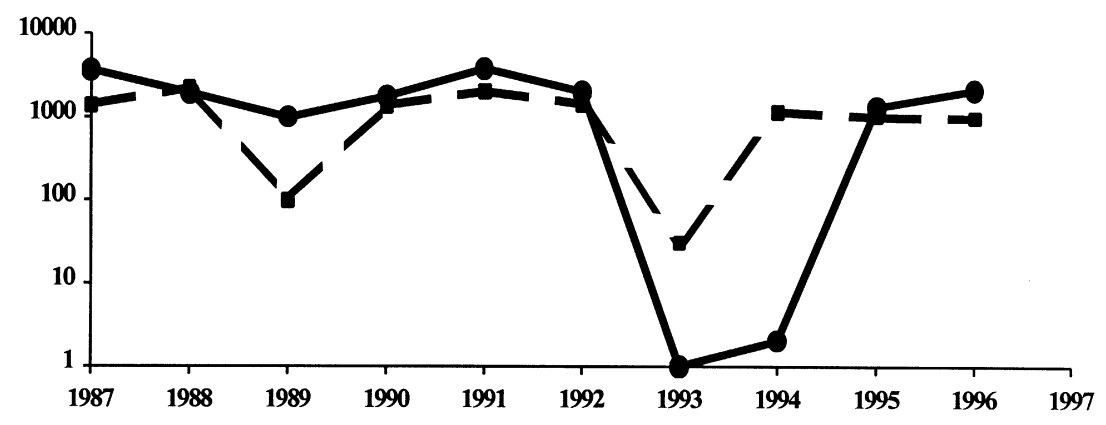

(c) Two Treatments

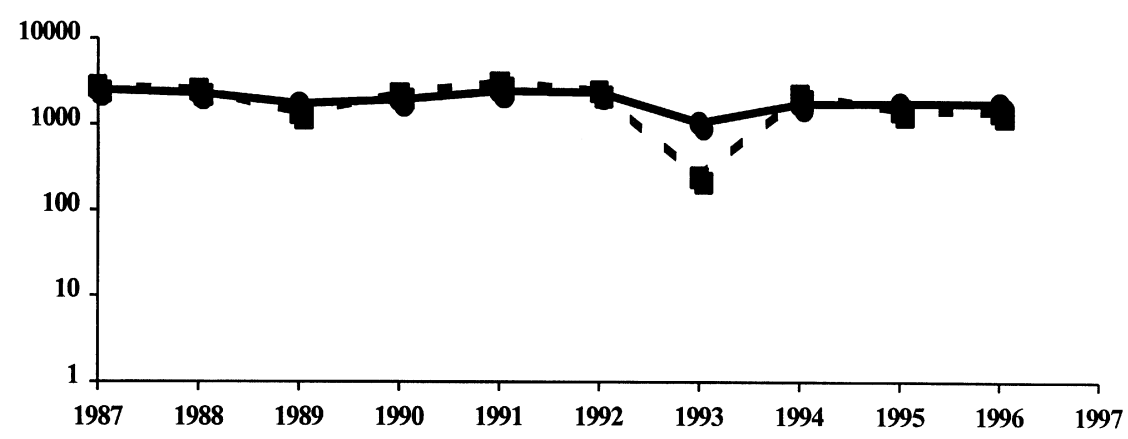

Figure 6.6 Experimental treatment of grouse with anthelmintic just prior to the population crash reduces the severity of the crash (numbers of grouse shot are expressed in logarithms of numbers +1 ). The experiment was conducted on four treated populations, two treated once in 1989 and two treated twice, once in 1989 and once in 1993 (after Hudson et al. 1998). 
1999; but see Hudson et al. 1999). To some degree this is an argument over the semantics of the terms "sufficient and necessary," but there are two specific criticisms. First, bag records were used in the analysis and these may overestimate the variance in population size because hunters tend not to harvest at low densities. Thus, during our experiment, the control populations were not harvested when the populations were very low. A superficial examination of the data (figure 6.1) confirms that the variance does in fact increase when grouse densities are below $100 \mathrm{birds} / \mathrm{km}^{2}$. However, a more detailed analysis of the count data from our main study area shows that the variance falls with the mean, such that at low densities there was more variation between count areas than recorded at high densities. In this respect the variance is really in the count data rather than the bag records since, when grouse numbers fall, the population becomes aggregated in certain areas and is not so evenly distributed throughout the available habitat. As such, bag records may well provide a better reflection of what is happening at the population level than the more precise counts conducted over a small area. Of course, a full population count across the whole area would have been the best answer, but was clearly impractical.

The second criticism is that the oscillations are only reduced, and a residual oscillation remains that could be caused by some other mechanism. Again, this is somewhat semantic because the residual oscillation cannot be detected statically. Either way, our model predicts a residual oscillation even in populations where $20 \%$ of the birds are treated (see figure 6.5a). In other words, we expected the oscillations to be reduced not eliminated, and so the experimental results are in complete agreement with the hypothesized effect.

A third criticism is that the treatment would have killed the whole community of gut helminths and not just $T$. tenuis. Of course this is true. However, analysis of birds at the time of treatment indicated that other parasites were rarely present and, when they were, their numbers were low. Tapeworms, for example, are relatively rare in spring compared with autumn. Thus, although all gut helminths would have been killed by the treatment, the dominant parasite is without doubt $T$. tenuis. Even if there were synergistic interactions between parasites, this would tend to support rather than refute the parasite hypothesis.

In reviewing this paper Robert Moss raised another criticism, that the experimental results could also be explained by the kin-selection/spacingbehavior hypothesis. He argued that this hypothesis would predict more young per adult in the summer following treatment, which would be followed by enhanced recruitment the next spring, resulting in larger kin clusters and, thereby, enhanced recruitment in the following spring as well. Thus, he feels that our experiment cannot distinguish between the predictions of the parasite hypothesis and the kin-selection hypothesis. However, we feel that this scenario is irrelevant, since the parasites are the actual cause of these population changes. Interestingly, this interpretation was part of the original kinselection hypothesis proposed by Hudson et al. (1985). 


\subsection{Noncyclic Populations}

In many species, including red grouse, the tendency for populations to cycle varies from place to place and, indeed, from time to time. Understanding the differences between cyclic and noncyclic populations by comparative study provides a natural way of exploring alternative hypotheses. Some grouse populations, particularly those inhabiting small moors and the eastern side of the United Kingdom, where rainfall is low, are less likely to exhibit cyclic hunting records (Hudson et al. 1985, Hudson 1992). These drier eastern moors tend to be freely drained heath dominated by pure stands of heather, with little Sphagnum moss and, consequently, a shallow peat layer. In contrast, moors in wetter areas have a mixture of heather and grasses, a thick layer of Sphagnum moss, and a deep peat layer that may be up to several meters thick.

The free-living stages of trichostrongyle worms require moisture for development to the third-stage infective larvae. A film of moisture is also required to aid worm movement up the vegetation to where it can be ingested by its host (Saunders et al. 2000). As moisture levels decline, fewer infective stages are available to infect grouse (Saunders et al. 1999, 2000). Hudson et al. (1985) recorded significantly lower worm intensities from non-cyclic populations, where only $4 \%$ of the birds had harmful infections compared with $24 \%$ from cyclic populations. As there was no difference in the densities of birds in the two regions, we concluded that the differences in infection levels probably reflected differences in survival of free-living nematodes and the exposure of birds to the infective stages. Thus, the absence of grouse cycles on many freely drained heather moors is explained by, and provides support for, the parasiteinteraction hypothesis.

It is interesting that grouse populations in parts of Scotland have shown a reduced tendency to oscillate in recent years (Hudson 1992), a tendency that does not appear to be associated with large-scale changes in habitat. The explanation of this phenomenon requires consideration of other natural enemies, particularly birds of prey and the louping ill virus (see below).

\subsection{Louping III Virus}

Red grouse are killed by a variety of natural enemies besides the strongyle worm, and some of these may have a profound impact on the dynamics of grouse and nematode populations. The louping ill virus is transmitted between sheep and grouse by the sheep tick, Ixodes ricinus. The virus can cause $80 \%$ mortality in exposed grouse, whereas mortality in sheep is variable and depends on breed and history of exposure (Reid et al. 1978). Only sheep and red grouse are viraemic hosts, and permit the amplification of the virus within the host to a concentration that leads to subsequent infection of other uninfected ticks. In most moorland areas where sheep suffer from the virus, shepherds vaccinate their sheep and treat them with acaricides so, in reality, 
sheep play no role in the amplification of the virus. Grouse alone are unable to maintain the virus so a large mammalian host is required for female ticks to complete their lifecycle. As no vertical transmission occurs between female ticks and their eggs, the larval stage must first acquire the virus and then pass it on to the grouse in the subsequent nymphal stage. While grouse and sheep are the only viraemic hosts, others can play an important role in the tick lifecycle and amplify the virus (Hudson et al.). One of these is the mountain hare, Lepus timidus, which not only provides a suitable host for the female tick, but also allows nonviraemic transmission of the virus between cofeeding ticks (Jones et al. 1997). Thus, the level of exposure of grouse to the louping ill virus depends on the density of mountain hares in the region. Theoretically, it is possible for the virus to persist in the hare population alone in the total absence of grouse (Norman et al. 1999).

Louping ill mortality in red grouse occurs soon after the emergence of ticks in late spring and coincides with the production of young grouse, leading to significant mortality in young birds during early June. This, in turn, results in infected grouse having lower breeding success, lower bag records, and lower breeding densities of grouse (figure 6.7). Reduction in the production of young leads to a population growth rate that can be negative and, in some populations, numbers are only maintained by the immigration of grouse in the following winter (Hudson 1992). Not surprisingly, this heavy mortality and resultant low population density is followed by lower levels of nematode infection and, consequently, by a reduced tendency to cycle. In passing it should be noted that not all populations of grouse are exposed to ticks and not all tick populations carry the louping ill virus.

\subsection{Predators}

Grouse moor keepers are employed by the majority of privately owned estates to remove predators that take red grouse, principally the fox, Vulpes vulpes, and the carrion crow, Corvus corone (Hudson and Newborn 1995). Historically, this has included all predator species, although birds of prey and some of the threatened mammalian predators are now legally protected. Nevertheless, most keepers believe that birds of prey have a significant impact on grouse populations, so illegal killing of species like hen harriers, Circus cyaneus, still occurs.

An intensive and extensive investigation has recently been completed on the relationship between grouse and hen harriers. While there is no clear numerical response of harriers to grouse populations, they do exhibit a type III functional response when feeding on grouse and, as is well known, this could have a stabilizing effect on grouse population dynamics (Redpath and Thirgood 1999). The settlement of breeding harriers in relation to prey availability is positively related to the density of meadow pipits, indicating they breed in areas where pipits are abundant. Meadow pipits are a major food for the smaller males but, once established, the larger females tend to feed on red 
(a)

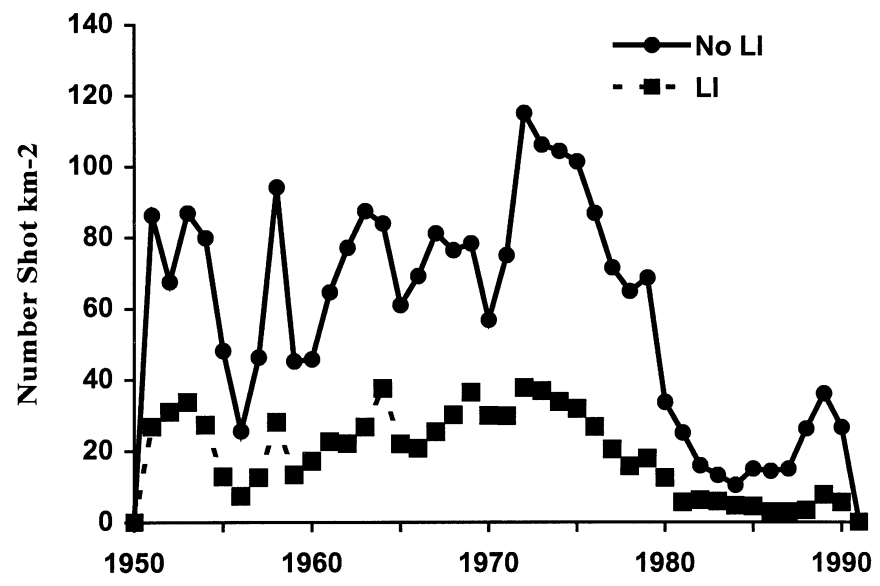

(b)

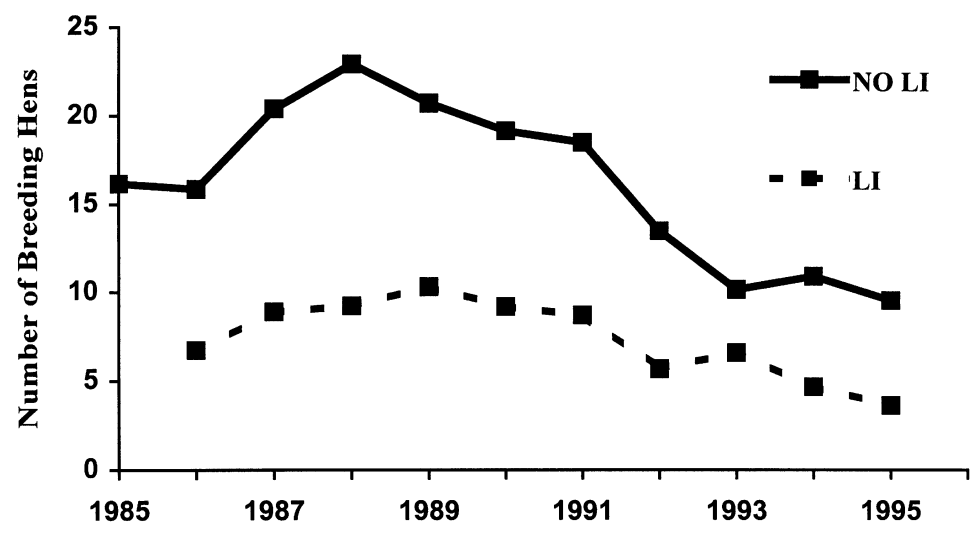

Figure 6.7 Population changes in red grouse infected with louping ill compared with uninfected populations. (a) Numbers harvested per annum per square kilometer. (b) Numbers of breeding adults.

grouse chicks (Redpath and Thirgood 1999). Following total protection of hen harriers on one estate, the population grew to 22 breeding harriers and the red grouse population fell. Although the initial decline was due to the regular grouse cycle, areas without harriers went through the normal increase phase while those with harriers continued to decline (figure 6.8). This is what is expected from a generalist predator with a type III functional response when the prey species becomes sparse - the "predator trap" or "predator pit."

Hudson et al. (1992a,b) examined the interaction between parasites, grouse, predators, and game keepers, and found an inverse relationship between keeper density and fox density, presumably because keepers killed 


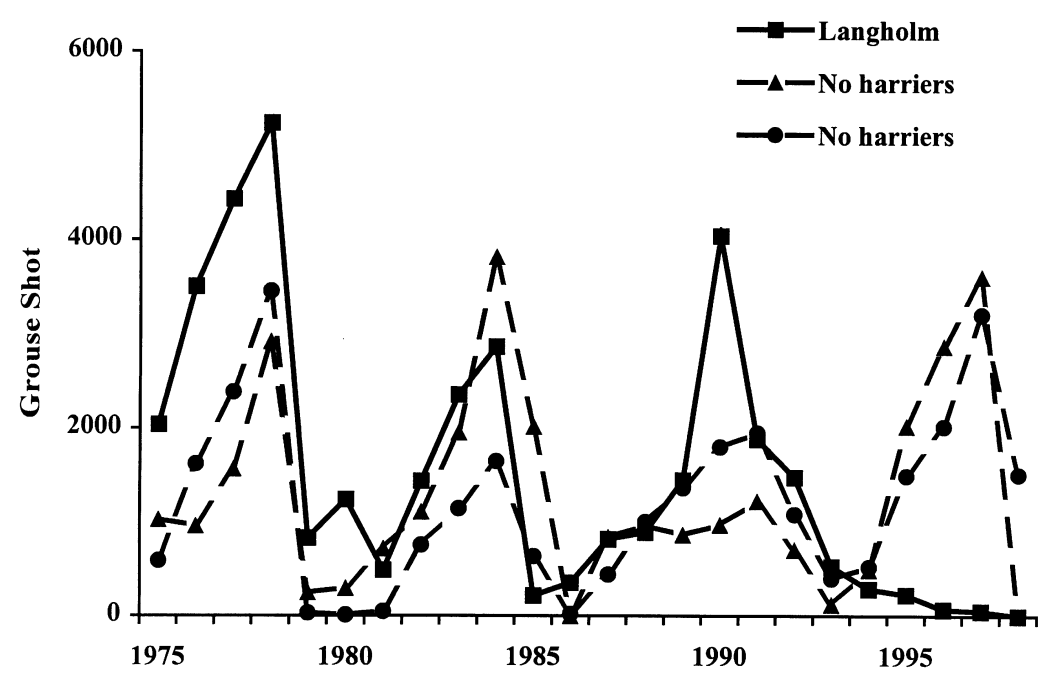

Figure 6.8 Numbers of grouse shot from the Langholm population following the protection of hen harriers in 1992 compared with two neighboring populations not exposed to harrier predation. The populations fluctuated in synchrony before the hen harriers became established, but subsequently the grouse numbers failed to rise at Langholm (after Thirgood et al. 1999).

most of them. In addition, the greater the density of keepers, the larger the harvest of grouse and the higher the intensity of worm infections. This implies that the removal of predators increases grouse populations and also results in higher parasite intensities.

To investigate whether parasites made the grouse more vulnerable to predation, dogs were used as artificial predators. Normally, trained pointing dogs can locate grouse at distances of up to and even more than $50 \mathrm{~m}$, since grouse like many gamebirds produce a characteristic strong scent from their cecae. However, when female grouse start incubating young, they stop producing cecal feces, and dogs can walk within centimeters of them without detecting their presence. The cecae are also the site of infection by $T$. tenuis. Hudson et al. (1992b) postulated that parasitism may affect scent emission, making grouse vulnerable to predators during incubation. To test this hypothesis, trained pointing dogs were used to locate two groups of grouse. In one group, individuals had been randomly treated with an anthelmintic prior to the breeding season. In the other group, grouse were given water instead of the anthelmintic. Observers searching for nests by sight found them at random and in equal proportions, but dogs selectively found the nests of untreated red grouse, supporting the hypothesis that parasitic infections make the grouse more vulnerable to predators.

Incorporating selective predation into the model results in the removal of heavily infected grouse from the population, reduces the intensity of parasitism, and leads to an increase in the grouse population (figure 6.9a). In addition, 
increased selective predation dampens the cycles (figure 6.9b). Notice that the effect of predators is nonlinear, with low to moderate numbers having a positive effect on grouse equilibrium densities, but high numbers having a negative effect.

\subsection{Harvesting}

Hunting is another form of mortality that reduces the growth rate of grouse populations. Like predators and virus infections, we might expect harvesting

(a)

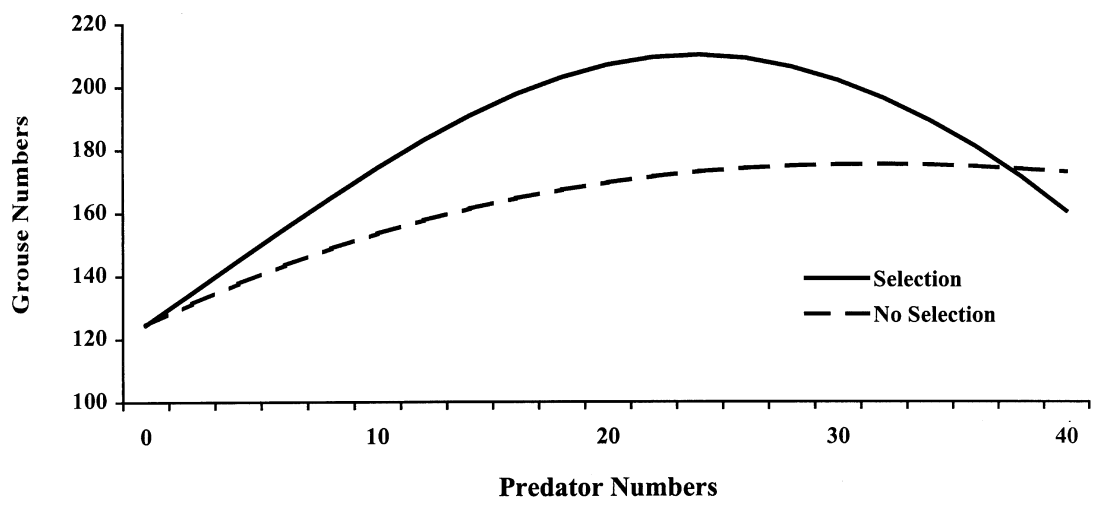

(b)

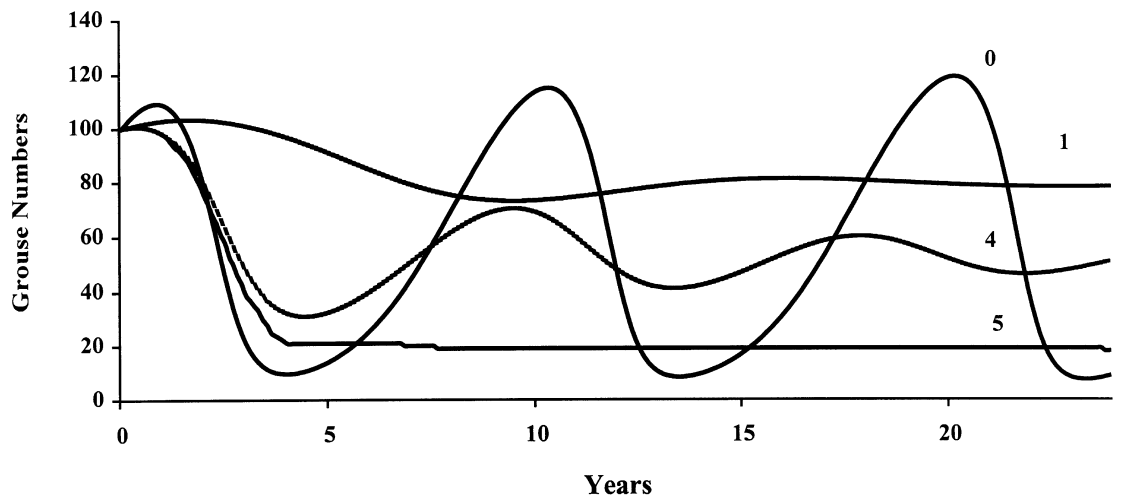

Figure 6.9 The influence of predation on the dynamics of red grouse populations as predicted by the grouse model. (a) Low to moderate rates of predation have a large impact on the worm population relative to their impact on the grouse population, leading to a release from worm-induced mortality and an increased grouse population. This is more marked when the predators selectively take the heavily infected grouse. (b) Simulations with the model illustrating the dampening effects of predation levels from 0 to 5 . 
to also have a stabilizing effect on grouse dynamics. The fact is, however, that grouse population fluctuations occur in the presence of hunting. The probable reason for this is that worm recruitment generally occurs just prior to the shooting season, so that hunting has little effect on the density-induced negative feedback responsible for the grouse cycle (Hudson 1986b).

\subsection{Discussion and Summary}

Populations of harvested red grouse exhibit cyclic fluctuations in abundance that vary in period and amplitude. We examined the hypothesis that the parasitic nematode $T$. tenuis increases numerically in response to grouse density, reduces the breeding success of female grouse and, through this delayed negative feedback loop, generates the cycles of abundance in grouse populations. Experimental studies of individual grouse confirmed that parasites reduce brood production. Realistic models of the parasite-host interaction generate cycles of similar period and amplitude to those observed in the field. Large-scale experiments conducted at the population level show that suppression of parasite infections greatly reduces the amplitude of the population cycle. Noncyclic populations were found to have lower infection levels, probably because habitat conditions reduced infection rates. Moderate levels of selective predation on heavily infected grouse dampens the cycles and increases the overall abundance of grouse. Natural enemies such as hen harriers and the tick-borne virus that causes louping ill disease reduce the survival of young grouse and tend to dampen oscillations. Harvesting does not seem to have this effect, probably because the period of worm recruitment occurs after chick mortality and before harvesting. None of the evidence discussed above is inconsistent with the hypothesis that population cycles in the red grouse are caused by delayed negative feedback between grouse and nematode parasite populations.

The significant role of parasites in causing red grouse cycles may well be a direct consequence of the activity of keepers protecting grouse from predators; that is, once predators are removed, the increasing population is subject to increasing levels of worm infection, which then cause reduced breeding production and a cyclic decline. Some workers consider this to be a rather exceptional case. However, there are a number of other cases where parasites are thought to play some role in population cycles. For example, there is increasing evidence that food quality interacting with parasitic nematodes is responsible for Soay sheep oscillations on St. Kilda (Gulland 1992); rock partridges exhibit unstable dynamics in northern Italy (Cattadori et al. 1999) that appear to be associated with infection by parasitic geohelminths (Rizzoli et al. 2000); population cycles of willow ptarmigan in Norway seem to be associated with the community of parasites that infect them (Holmstad and Skorping 1998); and, finally, unstable dynamics in Svalbard reindeer appear to be caused by the effects of gut helminths (Halvorsen and Bye 1999). The general pattern that emerges from all these examples is that there is a single host-parasite interac- 
tion where the parasite induces reduced breeding production. However, where other hosts play a significant role in the parasite lifecycle, the dynamics become more stable (Hudson and Greenman 1998).

This is not to say that red grouse cycles, or indeed cycles in any grouse species, are always caused by parasites. Such an extrapolation is risky at best. Unfortunately, there is currently no sound experimental evidence from other areas to test the hypotheses. There is, however, evidence that predators may play a significant role in some cyclic populations. For example, detailed studies over 16 years strongly suggest that the dynamics of rock ptarmigan in Iceland are destabilized by gyrfalcon predation (Nielsen 1999). What we can probably say with confidence is that one type of natural enemy, the parasites, can have an important destabilizing effect on some grouse populations some of the time. Other natural enemies and resources, together with demographic features like spatial social structuring and age structure, can interact with stochastic and seasonal variations to influence the final pattern of fluctuation.

\section{ACKNOWLEDGMENTS}

We would like to thank all our scientific colleagues for their support and stimulating discussion on the subject of red grouse population cycles, especially Steve Redpath, Simon Thirgood, Bryan Grenfell, and Francois Mougeot. We also extend our gratitude to the landowners and keepers who allowed us to work on their land, and our warmest admiration to the dogs that actually did the fieldwork with enthusiasm and dedication. Finally we would also like to thank Robert Moss and Alan Berryman for their constructive comments and editorial suggestions.

\section{REFERENCES}

Anderson, R. M. and R. M. May. 1978. Regulation and stability of host-parasite interactions. I. Regulatory processes. J. Anim. Ecol. 47: 219-249.

Cattadori, I. M. C., P. J. Hudson, S. Merler, and A. P. Rizzoli. 1999. Temporal and spatial dynamics of rock partridge populations (Alectoris graecae) in northern Italy. J. Anim. Ecol. 68: 540-549.

Cobbold, T. S. 1873. The grouse disease. The Field, London. p. 15.

Dobson, A. P. and P. J. Hudson. 1992. Regulation and stability of a free-living hostparasite system, Trichostrongylus tenuis in red grouse. II. Population models. J. Anim. Ecol. 61: 487-498.

Dobson, A. P. and P. J. Hudson. The interaction between the parasites and predators of red grouse Lagopus lagopus scoticus. Ibis 137 (Suppl. 1): 87-96.

Gulland, F. M. D. 1992. The role of parasites in Soay sheep (Ovis aries) mortality during a population crash. Parasitol. 105: 493-503.

Gurney, W. S. C. and R. M. Nisbett. 1998. Ecological dynamics. Oxford University Press, Oxford.

Halvorsen, O. and K. Bye. 1999. Parasites, biodiversity and population dynamics in an ecosytem in the High Arctic. Vet. Parasit. 84: 205-227. 
Holmstad, P.R. and A. Skorping. 1998. Covariation of parasite intensities in willow ptarmigan, Lagopus lagopus L. Can. J. Zool. 76: 1581-1588.

Hudson, P. J. 1986a. The effect of a parasitic nematode on the breeding production of red grouse. J. Anim. Ecol. 55: 85-94.

Hudson, P. J. 1986b. The red grouse, the biology and management of a wild gamebird. The Game Conservancy Trust, Fordingbridge, $250 \mathrm{pp}$.

Hudson, P. J. 1992. Grouse in space and time. The Game Conservancy Trust, Fordingbridge, $250 \mathrm{pp}$.

Hudson, P. J. and A. P. Dobson. 1996. Transmission dynamics and host-parasite interactions of Trichostrongylus tenuis in red grouse. J. Parasitol. 83: 194-202.

Hudson, P. J. and J. V. Greenman. 1998. Parasite mediated competition. Biological and theoretical progress. Trends Ecol. Evol. 13: 387-390.

Hudson, P. J. and D. Newborn. 1995. A handbook of grouse and moorland management. The Game Conservancy Trust, Fordingbridge, $169 \mathrm{pp}$.

Hudson, P. J., A. P. Dobson, and D. Newborn. 1985. Cyclic and non-cyclic populations of red grouse: a role for parasitism? In D. Rollinson and R. M. Anderson (Eds.) Ecology and genetics of host-parasite interactions. Academic Press, London, pp 79-89.

Hudson, P. J., A. P. Dobson, and D. Newborn. 1992a. Do parasites make prey vulnerable to predation? Red grouse and parasites. J. Anim. Ecol. 61: 681-692.

Hudson, P. J., D. Newborn, and A. P. Dobson. 1992b. Regulation and stability of a free-living host-parasite system, Trichostrongylus tenuis in red grouse. I. Monitoring and parasite reduction experiments. J. Anim. Ecol. 61: 477-486.

Hudson, P. J., R. Norman, M. K. Laurenson, D. Newborn, M. Gaunt, H. Reid, E. Gould, R. Bowers, and A. P. Dobson. 1995. Persistence and transmission of tickborne viruses: Ixodes ricinus and louping-ill virus in red grouse populations. Parasitol. 111: S49-S58.

Hudson, P. J., E. A. Gould, M. K. Laurenson, M. Gaunt, H. W. Reid, J. D. Jones, R. Norman, K. MacGuire, and D. Newborn. 1997. The epidemiology of louping-ill, a tick borne viral infection of grouse and sheep. Parasitologia 39: 319-323.

Hudson, P. J., A. P. Dobson, and D. Newborn. 1998. Prevention of population cycles by parasite removal. Science 282: 2256-2258.

Hudson, P. J., A. P. Dobson, and D. Newborn. 1999. Population cycles and parasitism. Science 286: 2425.

Jenkins, D., A. Watson, and R. G. Miller. 1963. Population studies on red grouse, Lagopus lagopus scoticus (Lath.) in north-east Scotland. J. Anim. Ecol. 32: $317-$ 376.

Jones, L. D., M. Gaunt, R. S. Hails, K. Laurenson, P. J. Hudson, H. Reid, P. Henbest, and E. A. Gould. 1997. Efficient transfer of louping ill virus between infected and uninfected ticks cofeeding on mountain hares (Lepus timidus). Med. Vet. Entomol. 11: $172-176$.

Lack, D. 1954. The natural regulation of animal numbers. Oxford University Press, Oxford.

Lambin, X., C. J. Krebs, R. Moss, N. C. Stenseth, and N. G. Yoccoz. 1999. Population cycles and parasitism. Science 286: 2425.

Laurenson, M. K., P. J. Hudson, K McGuire. S. J. Thirgood, and H. W. Reid. 1998. Efficacy of acaricidal tags and pour-on as prophylaxis against ticks and loupingill in red grouse. Med. Vet. Entomol. 11: 389-393.

Lovat, L. 1911. The grouse in health and disease. Smith, Elder and Co., London, p. 512. 
MacDonald, D. G. F. 1883. Grouse disease: its causes and remedies. W. H. Allen and Co., London, p. 189.

Mackenzie, J. M. D. 1952. Fluctuations in the numbers of Tetraonidae. J. Anim. Ecol. 21: $128-153$.

May, R. M. 1976. Theoretical ecology. Principles and applications. Blackwell Scientific, Oxford.

May, R. M. and R. M. Anderson. 1978. Regulation and stability of host-parasite interactions. II. Destabilizing. J. Anim. Ecol. 47: 249-268.

Moran, P. A. P. 1952. The statistical analysis of gamebird records. J. Anim. Ecol. 21: $154-158$

Moss, R. and A. Watson. 1991. Population cycles and kin selection in red grouse Lagopus lagopus scoticus. Ibis Suppl. 1: 113-120.

Nielsen, O. K. 1999. Gyrfalcon predation on ptarmigan: numerical and functional responses. J. Anim. Ecol. 68: 1034-1050.

Norman, R., R. G. Bowers, M. E. Begon, and P. J. Hudson. 1999. Persistence of tick borne virus in the presence of multiple host species: tick reservoirs and parasite mediated competition. J. Theor. Popul. Biol. 200: 111-118.

Potts, G. R., S. C. Tapper, and P. J. Hudson. 1984. Population fluctuations in red grouse: analysis of bag records and a simulation model. J. Anim. Ecol. 53: 21-36

Redpath, S. M. and S. J. Thirgood. 1999. Numerical and functional responses of generalist predators: harriers and peregerines on grouse moors. J. Anim. Ecol. 68: 879-892.

Reid, H. W., J. S. Duncan, J. D. P. Phillips, R. Moss, and A. Watson. 1978. Studies of louping ill virus in wild red grouse (Lagopus lagopus scoticus). J. Hygiene 81: 321329

Ricklefs, R. E. 1979. Ecology. Thomas Nelson, Melbourne.

Rizzoli, A., P. J. Hudson, M. T. Manfredi, F. Rosso, and I. M. C. Cattadori. 2000. Intensity of nematode infections in cyclic and non-cyclic rock partridge populations. Parasitologia 41: 561-565.

Saunders, L. M., D. Tompkins, and P. J. Hudson. 1999. Investigating the dynamics of nematode transmission to the red grouse (Lagopus lagopus scoticus): studies on the recovery of Trichostrongylus tenuis larvae from vegetation. J. Helminthol. 73: 171-175.

Saunders, L. M., D. Tompkins, and P. J. Hudson. 2000. Spatial aggregation and temporal migration of free-living stages of the parasitic nematode Trichostrongylus tenuis. Funct. Ecol. 14: 468-473.

Shaw, J. L. 1988. Arrested development in Trichostrongylus tenuis as third stage larvae in red grouse. Res. Vet. Sci. 48: 256-258.

Shaw, D. J. and A. P. Dobson. 1995. Patterns of macroparasite abundance and aggregation in wildlife populations: a quantitative review. Parasitol. 111: 111134.

Thirgood, S. J., D. Haydon, P. Rothery, P. Redpath, I. Newton, and P. J. Hudson. 1999. Habitat loss and raptor predation: disentangling long- and short-term causes of red grouse declines. Proc. Roy. Soc. 267: 651-656.

Watson, H., D. L. Lee, and P. J. Hudson. 1987. The effect of Trichostrongylus tenuis on the caecal mucosa of young, old and anthelmintic treated wild red grouse Lagopus lagopus scoticus. Parasitol. 94: 405-411.

Wynne-Edwards, V. C. 1986. Groups selection. Blackwell Scientific, Oxford. 